The efiects of pollution by oxidizable organic matter are usually quite different. Immediately below the point of discharge, and before decomposition has begun, the effect on the distribution of the flora and fauna (including fish) may be very small. Lower down the stream, where decomposition is proceeding actively, with a lowering of the oxygen tension and deposition of sludge, the normal fauna is replaced by a typical community consisting of 'sewage fungus', Tubificidæ, and larvæ of Chironomidæ of the plumosus type. Farther downstream Chironomidæ of other groups and leeches-particularly Herpobdella octoculata-appear. At this stage sewage fungus disappears and with it the black deposit of sludge on the river bed. The numbers of Chironomidæ and Tubificidæ then decline, and Asellus becomes a characteristic member of the fauna. The next stage, farther still downstream, is usually marked by the appearance of pulmonate molluses, after which the animals of the community normal to the unpolluted river replace those of the polluted stretch. At this stage fish are usually found.

Prof. W. H. Pearsall pointed out that, from the botanical aspect, investigations of river pollution have been concerned mainly with attempts to employ different plants as indicators of the stages of organic pollution and of subsequent oxidation. He illustrated the sensitivity of these tests by referring to the effects cf small concentrations of organic matter on the algal population of a stream. The products of oxidation of organic matter in flowing water, mainly carbonates, nitrates and phosphates, have a great effect on the luxuriance of plant growths and thus lead to accumulation of organic muds, even though the polluting liquids themselves may lack visible turbidity. The animal population is also afiected by the presence of these muds and the anaerobic conditions they may introduce.

The principal botanical problem associated with such pollution is, however, connected with the large quantities of compounds of nitrogen and phosphorus discharged to surface waters in sewage effluents and their loss to the national economy. Methods by which these materials can be recovered and used in agriculture are thus very important. One possibility would be to pass the effluent through shallow lakes containing such plants as Elodea, which would grow very rapidly under these conditions and which might be harvested and used as a green manure. Another possible method of utilization might be to pass the sewage effluent through water meadows containing such plants as Sparganium or Glyceria, which could be grazed by stock or possibly harvested and used for making silage.

Mr. H. Jones described the pollution of the rivers of North Cardiganshire-particularly the River Rheidol-by compounds of lead and zine leached from spoil banks of mines. The active polluting substances are lead sulphate and zinc sulphate, which are formed by oxidation of the sulphides at the surface of the spoil banks. In the drainage area of the Rheidol, mining on a large scale ceased in 1922; the river at that time was almost barren, containing only small numbers of Algæ and Bryophytes, with occasional insect larvæ and Crustacea. By the summer of 1923, however, the river contained representatives of all the usual groups of aquatic animals with the exception of Mollusca and fishes; at this time Callitriche verna and Ranunculus aquatilis appeared in the river. Although mining has generally ceased, pollution still occurs, however, during periods of flood. Intensive work has been undertaken at University College, Aberystwyth, to investigate methods by which the river could be restored to its natural condition. It was shown by E. W. Jones that addition of calcium carbonate and superphosphate in comparatively large amounts to soil impregnated with the metals greatly improved the growth of vegetation by reducing the concentration of available lead and zinc below the toxic level. Trees of several species were successfully grown in the affected areas, the two most resistant of those tried being birch and pine. Best results were obtained when trees about six feet high were transplanted, and when they were planted in pockets of uncontaminated soil. During recent years there has been a remarkable improvement in the condition of the River Rheidol, which has now been extensively re-colonized by aquatic plants, particularly Callitriche intermedia and Glyceria fluitans. Migratory trout and salmon are now found in the river, and freshwater trout have been successfully introduced.

\section{INDUCTION OF MUTATIONS} $\mathrm{T}$ the recept Nowcastle meeting of the British
jointly held
of mutatiens.
reviewed the of on the induction of cytoplasmic
changentory the action of chemical agents. He pointed
out thad when such changes are induced in lower
orghtsms, as in yeasts, they often appear to be relatively stable, indicating that the cytoplasm in these organisms is incompletely subordinated to the control of the nucleus. In higher organisms, on the other hand, cytoplasmic changes are of limited duration (Dauermodifikation), although they may last through several sexual generations.

Two important conditions must apparently be satisfied in order to induce cytoplasmic changes, particularly in higher organisms. (1) The external agents must act for a relatively long time, because, unlike the nuclear genes, the genetically important cytoplasmic determinants are thought to be in a chemical equilibrium. (2) The influence of the nucleus on the cytoplasm must be at the minimum -a condition which can be attained by keeping the nucleus arrested in its mechanically active phase, while at the same time allowing cytoplasmic synthesis to proceed.

Dr. J. M. Thoday (Sheffield) discussed the influence of oxygen on radiation-induced chromosome struc. tural change and indicated the advances that have been made towards elucidating the sequence of events involved in the formation of chromosome structural changes initiated by ionizing radiations. While these advances have been largely concerned with the later phases of the sequence, he thought it possible that the discovery of the influence of oxygen might lead to knowledge of some of the active chemical substances involved in the earliest phases. This would help to bring radiation work into line with that being done on chemical mutagens.

Dr. Thoday then outlined the target theory of radiation breakage, and presented results, obtained with Vicia faba, to demonstrate that the target theory stands up to some of the criticisms that have been levelled against it. However, the target theory can only account for the variation in yield of aberrations 
with progress of the mitotic cycle on one of two assumptions, neither of which seems valid. It thus becomes necessary to suppose that the effect of $\mathbf{a}$ particle within the target volume is not to produce a complete break, but to initiate a potential break which may lead to separation immediately if mechanical conditions, etc., are favourable, may remain latent as in Trillium metaphases, or may lead to restitution without separation ever occurring. The proportion of potential breaks that separate and become primary breaks (detectable through their influence on the frequency of exchanges) will vary according to the physiological state of the cell, which itself can be altered by radiation. Dr. Thoday presented evidence that, in Vicia, oxygen greatly increases the yield of aberrations obtained with a given dose of X-rays, but does not affect, or affects very little, that obtained with a given dose of $\alpha$-rays, and pointed out that this parallels the effect of oxygen on the production of hydrogen peroxide from water by these radiations. It thus seems likely that hydrogen peroxide or some related radicals play a part in the formation of aberrations; but it is impossible to say whether hydrogen peroxide is the agent producing potential breaks, or whether it affects the yields indirectly by some effect on the physiological state of the cell that alters the frequencies of separation of potential breaks formed in some other way. Dr. Thoday also mentioned some preliminary results that seem to show $E$. coli to be less sensitive to $\mathrm{X}$-rays if irradiated in the absence of oxygen. The effect of oxygen may therefore be quite general.

Dr. T. G. Carter (Edinburgh) considered the induction of mutations in small mammals. Following the original work of H. J. Muller on flies, the probability that radiations can also induce mutations in man has led, during the past twenty years, to numerous detailed studies on the effects of X-rays on mice and other small mammals.

At least four visible inheritable defects have been induced in mice by radiations, all by Paula Hertwig in Germany during 1938-39. Their main features were lethal anæmia, fusion of the toes (syndactyly), loss of toes (oligodactyly) and a nervous disorder (kreisler). A fifth visible defect, microphthalmia, combined with lack of pigment in the coat, may also have been induced by the radiation. Invisible hereditary defects in mice, manifesting themselves as semi-sterility, were first reported by Snell in the United States in 1935; he induced them by both $\mathrm{X}$-rays and neutrons from the California cyclotron.

These studies were intensified in the United States during the War and extended to include gamma-rays from radioactive materials, and neutrons from atomic piles. The main object of the war-time work was to provide a basis for rules to safeguard the health of workers on atomic projects and to ensure that they should not become sources of undesirable radiation-induced hereditary traits which might then spread through the population during succeeding centuries. Conclusions drawn from this work are summed up in the following sentence from an article by R. D. Evans in Science of March 1949. "From the appropriate mathematical theory, and the experimental data now available, it seems safe enough to conclude that no detectable increase in hereditary abnormalities is likely to result, even after many generations, if a small fraction of the population receives daily doses up to $0 \cdot 1$ roentgen per day."
The paper by Dr. C. Auerbach (Edinburgh) described some of her work on the production of mutations by chemical means, which was first achieved during the War. Following on the suggestion of Dr. J. M. Robson, of the Pharmacological Department of the University of Edinburgh, it was decided to try the effect of mustard gas for mutagenic activity. This suggestion was based on observations of the similarity between mustard-gas burns and X-ray burns. Since it was known that the typical action of X-rays is due to effects on the chromosomes, it seemed possible that the same might be true for the action of mustard gas. In addition, Dr. Robson had found that vaginal epithelium of mice which had been treated with a weak solution of mustard gas failed to respond to ostrogen by the usual proliferation, an indication that mustard gas inhibits cell division. The first experiments of Robson and Auerbach in the winter of 1940 on Drosophila showed that doses which were not lethal to the flies had a sterilizing effect on both males and females. During the first days after treatment, some progeny were produced, but many of the eggs laid by treated females or inseminated by treated males failed to hatch; afterwards, with a sufficiently high dose, both sexes became completely sterile. This agreed well with observations on X-rayed animals. It indicated that after mustard gas, as after irradiation, sterility has two separate causes: (1) inhibition of cell division in the gonads so that no replacement of expended gametes takes place; and (2) embryonic death after treatment of either parent. Embryonic death after X-radiation is due to chromosomal disturbances in the treated gamete; possibly the same might apply to mustard gas.

The first crucial test for the mutagenic action of mustard gas was done early in 1941, using the socalled ClB test, whereby the percentage of sexlinked lethal mutations can be accurately determined. In untreated laboratory stocks, mutations to sexlinked lethals arise spontaneously in less than one per cent of gametes; in the controls to the first ClB test, there were $0 \cdot 3$ per cent spontaneous lethals. In the treated series, the frequency of sexlinked lethals was seven per cent. In subsequent experiments with bigger doses, even higher mutationrates were obtained. There could thus be no doubt of the mutagenic efficiency of mustard gas ; mutation. rates of this order had previously been obtained only with ionizing radiations. Further analysis showed that mustard gas produces all the genetical effects which occur after X-radiation : visible and lethal gene mutations, small and large deletions, inversions, translocations, etc. Small deletions form about the same proportion of mustard gas-induced lethals as of X-rayinduced lethals. Large rearrangements, on the other hand, which require two independent chromosome breaks with subsequent reunion of broken ends, are considerably less frequent after mustard gas than after X-rays. This shortage is particularly pronounced for translocations, that is, exchanges of pieces between chromosomes. We do not yet know whether mustard gas is less efficient than X-rays in breaking the chromosomes, or whether it interferes with the reunion of broken ends so that fewer rearrangements can be recovered. A second difference from X-ray effects is the high percentage of mutations which first appear as mosaics. This and other observations of a similar nature suggest that mustard gas, in contrast to X-rays, sometimes has a delayed mutagenic effect, causing mutations not in the 
treated chromosomes themselves, but in their descendants.

Chemically, mustard gas belongs to the group of the so-called mustards, several of which were found to be mutagens of great power. The inhibition of mitosis by the mustards is used in the treatment of certain types of malignant disease. The same is true for urethane, which likewise was found to be a mutagen. Phenol, or perhaps a contaminant of phenol, has given high frequencies of mutations in experiments by Hadorn and his collaborators. Formalin, mixed with the food of Drosophila, is a highly efiective mutagen. The fact that one weak, but decidedly positive mutagen, mustard oil, occurs naturally in Brassica plants raises the question whether naturally occurring mutagens have played a part in evolution.

\section{6}

\section{THE CENTENARY OF FINLAND'S INSTITUTE OF TECHNOLOGY By SiR ALFRED EGEFFoN, F.R.S.}

$\Delta$ STATUTE issuedon 147 prescribed the foundation of such schoolsin Finland as would provide "youths who wish to havel, career in Industry with an opportunity for the redessary training". The Technical Schp hftrunded in Nelsinki was opened on January 15, I 49 So tes born the present Finland's Institute of Aftaology, which has just celebrated its centenary.

Thê Institute has experienced several phases of develorment. In 1872 the Technical School became a Polytechnic School with five departments, architecture, civil engineering, mechanical engineering, chemical technology and surveying. In 1879 the School became a Polytechnic Institute admitting only matriculated students, and in 1908 its name was changed to "Finland's Institute of Technology" and it was placed under the control of the Ministry of Trade and Industry. Administration is in the hands of the Rector, who is chairman of an Administrative Council. There is also an advisory body appointed by the Government. Diplomas are given in archi. tecture and in engineering (civil, mechanical, electrical, chemical ; wood technology, mining and metallurgy, and technical physics). The syllabus is drawn up on the basis of a course of four and a half years. The examination is in two parts, a preliminary or intermediate examination in the basic sciences, followed in the second period by specialized training and $a$ diploma thesis. Practical training in industries with which the Institute is related is included in the course. Opportunity for postgraduate studies are provided and lead after a considerable period of study to the degree of doctor of technology. The diploma courses are designed on the principle that in a country like Finland with a comparatively small population $(3.8$ millions) the need for technical experts is limited compared with the larger countries, and so the aim is to give students a good general theoretical basis in engineering or architecture, with opportunity for advanced specialized training in a wide choice of subjects.

The Mechanical Engineering Department of the Institute is the largest, with about 580 students. The Department has four separate sections : mechanical engineering, ship-building, aeroplane construction and textile engineering. In chemical engineering, the stress is laid on the basic training in chemistry and in engineering; practical experience is gained in works rather than attempting to operate chemical plant in the Institute, which seems a wise procedure. There is a separate and very active Department of Wood Technology relating to Finland's major industry, divided into the sections, chemical, mechanical and paper, and well equipped with appliances for testing and treatment of wood. The Chemistry Department is well known for researches (of Prof. G. Komppa and others) on the chemistry of terpenes. The Department of Architecture has also a great reputation; Prof. J. S. Sirén is the present head.

Teaching is provided in Finnish and in Swedish. There are fifty-two professors on the stafi of the Institute and 2,200 students (of whom nearly 200 are women). All students enrolled belong to the Students' Corporation, which promotes the intellectual efforts of its members and assists their finances. Within this Corporation, each Department of the Institute has its own students' guilds based on the subjects studied and their special interests, such as the choir, the orchestra, the athletic society and the girl student club. These free activities of the students have been helpful in preparing them for public life; there is much innate talent in the Finnish students, and the standard of achievement in their many activities is remarkably high.

The main building of the Institute dates from about 1875 ; but it has been largely rebuilt and greatly extended by the addition of new buildings (for example, the Mechanical Engineering Laboratory). The principal building, with its fine hall and council room, was considerably damaged during the Second World War, but has now been repaired; the new chemical laboratories were on view on the occasion of the centenary. The present site is pleasant; it opens on to a wide space leading to one of Helsinki's many quays. Looking to the future, however, plans are afoot for buildings on an altogether new site.

The Institute has trained many of Finland's leading men-industrialists, architects, engineers and men of science- and it was no wonder that the celebration of the centenary was a momentous occasion in Helsinki. The main festival was held on September 13 in the hall of the University and was attended by President Paasikivi. General Mannerheim was present also. Addresses were handed to the Rector by representatives of many institutes of technology in foreign countries, including the Imperial College, London, and the Victoria University, Manchester; Prof. Wright Baker represented the Victoria University. It would not have been consistent with Finland's contribution to the arts if this gathering in honour of its great centre of science and technology had taken place unaccompanied by music; not only were those who attended delighted by the music of Sibelius, but there was also the magnificently trained students' choir.

On the next day, a ceremony was held in the hall of the Institute for the conferment of degrees: Dr. K. T. Compton (U.S.A.), Prof. A. Engelund (Denmark), M. A. Perret (France), Sir Alfred Egerton (England), Prof. F. Vogt (Norway), Prof. H. Kreüger and Prof. R. Woxén (Sweden), and Prof. M. Reš (Switzerland) received the degree of doctor of technology honoris causa, along with Prof. A. I. Virtanen and other distinguished men of Finland. 